\title{
The effect of prior training on the contrafreeloading phenomenon
}

\author{
B. E. LENTZ and STEVEN L. COHEN \\ Bloomsburg State College, Bloomsburg, Pennsylvania 17815
}

\begin{abstract}
Pigeons were trained to peck a key for food on a variable-interval 1-min schedule. They were then given a choice between responding for food or eating freely available food from a cup in the rear of the chamber. Four pigeons were given consecutive choice tests after $6,12,24,48$, and 96 sessions of training, four pigeons were tested after 48 and 96 sessions, and four pigeons with extensive experience from a previous experiment were tested once. Response rates in the presence of free food increased as a function of previous training. The data suggest that amount of training affects contrafreeloading and that this variable may be partly responsible for the large variability in responding observed among studies examining responding in the presence of free food.
\end{abstract}

Jensen (1963) demonstrated that rats would respond for food while "free food" was concurrently available. Many studies have verified this "contrafreeloading" phenomenon (see Osborne, 1977, for a review) while examining such variables as schedules of reinforcement (e.g., Carder \& Berkowitz, 1970) and conditioned reinforcement (e.g., Alferink, Crossman, \& Cheney, 1973).

An outstanding feature of this research is the marked variability in results among studies (cf. Osborne, 1977). While some studies report high response rates or a strong preference for response-produced food in the presence of free food (e.g., Davidson, 1971; Neuringer, 1970), others report only minimal responding in the presence of free food (e.g., Hothersall, Huey, \& Thatcher, 1973). These studies differ in many ways (e.g., species, operants, etc.), and it is difficult to attribute the differing results to any one set of variables. Osborne (1977) has stated that the interexperimental variability can most likely be attributed to the degree of stimulus change that accompanies response-dependent reinforcement (e.g., Osborne \& Shelby, 1975) and to the nature of the prechoice training procedures. Prechoice training may involve varying the number of sessions or trials of response-dependent food before a choice test. Some studies have suggested that responding in the presence of free food increases as a function of the amount of prechoice training (Jensen, 1963; Jensen, Leung, \& Hess, 1970; Stolz \& Lott, 1964). Jensen (1963), for

Portions of this manuscript were read at the September 1976 meeting of the American Psychological Association in Washington, D.C. We wish to thank Aaron Polonsky for his help in this research. The first author is now at the Bucks County Association for the Blind, Newtown, Pennsylvania. Reprints may be obtained from the second author, Department of Psychology, Bloomsburg State College, Bloomsburg, Pennsylvania 17815. example, trained six groups of rats to barpress for food $40,80,160,320,640$, or 1,280 times before a choice test. The percentage of total food pellets obtained by responding increased as a function of the number of prechoice responses.

Other studies, however, have suggested that the amount of prechoice training plays only a minimal (if any) role in the contrafreeloading phenomenon (Bilbrey, Patterson, \& Winokur, 1973; Jensen et al., 1970; Leung, Jensen, \& Tapley, 1968). For example, Jensen et al. (1970) reported that rats are more likely to eat free food than to run for food in a runway if they are given prior running experience. Bilbrey et al. (1973) showed that undeprived naive pigeons will respond for food in the presence of free food at a rate that resembles the rates maintained by undeprived experienced pigeons. In addition, studies have also shown that naive animals can acquire a response in the presence of free food (e.g., Neuringer, 1969).

Because these two groups of studies differ from each other in so many respects, it is difficult to determine the factors that are responsible for the discrepant results. In light of this, the present experiment was conducted to assess the role of prior experience in the contrafreeloading effect. Pigeons were trained to peck a key for food under a variable-interval (VI) schedule of reinforcement. After a predetermined number of training sessions, choice tests were conducted in which pigeons could respond for food or eat freely available food.

\section{METHOD}

\section{Subjects}

One male White Carneaux (Bird 12), three male Silver King (Birds 4, 5, and 13), and four male (Birds 21, 22, 23, and 24) and four female (Birds 14, 17, 26, and 27) Burmingham Roller pigeons were maintained at $80 \%$ of their free-feeding weights. 
Birds $4,5,12$, and 13 had 177-284 sessions of previous experience under a fixed-interval $40-\mathrm{sec}$ schedule: These birds made up the "extended training" group. All other birds were experimentally naive.

\begin{abstract}
Apparatus
Two Lehigh Valley Electronics three-key pigeon chambers were used. The side keys were covered, and the center key was transilluminated by differently colored lights and forms. A minimum force of $.10 \mathrm{~N}$ operated the key. General illumination during sessions was provided by a $28-\mathrm{V}$ white houselight positioned on the left wall of the chamber. Electromechanical equipment controlled sessions.
\end{abstract}

\section{Procedure}

Pigeons' keypecking was shaped during the first session. In the second session responses were reinforced under a VI 1-min schedule; the first response after an average of 1 min produced $3 \mathrm{sec}$ access to mixed grain. During food presentations the food hopper was illuminated by white light, and the houselight and keylight were extinguished. The VI schedule contained 15 intervals derived from the Catania and Reynolds (1968) formulation. Sessions terminated after 60 reinforcers and were conducted 5 days/week.

After a number of sessions under the VI schedule, a choice test was conducted. During the test a tin dish (the same as that used in each bird's home cage) filled with $150 \mathrm{~g}$ of mixed grain was secured in the left rear of the chamber. The pigeon was placed in the chamber, and the houselight was turned on. Once the pigeon began eating, the key and the VI programmer were activated. A pigeon could eat freely available grain or respond for grain under the VI 1-min schedule. Test sessions lasted $120 \mathrm{~min}$ or 60 response-produced reinforcers, whichever came first. Pigeons were tested once, twice, or five times. After testing, pigeons were returned to their home cages and reduced once again to $80 \%$ of their free-feeding weights.

Pigeons $14,17,21,22,23,24,26$, and 27 pecked a green key. Pigeons $14,17,24$, and 27 were tested 23 h after $6,12,24$, 48 , and 96 sessions. Pigeons $21,22,23$, and 26 were tested after 48 and 96 sessions. The "extended training" pigeons were tested after 17 sessions under the VI schedule. Key illumination was varied for these birds; that is, Pigeon 4 pecked a red key, Pigeon 5 pecked a white circle on a dark background, Pigeon 12 pecked a white vertical line on a dark background, and Pigeon 13 pecked a green key.

\section{RESULTS}

The three major dependent variables in the present study included (1) time from the beginning of the test session until the first response, (2) response rate during the test, and (3) mean response rate for the five sessions before the test. The mean time until the first keypeck for all test sessions was $8.97 \mathrm{~min}$. This does not include the "extended training" test for Bird 12 (latency $70 \mathrm{~min}$ ) or the first test for Birds 24 (latency $100 \mathrm{~min}$ ) and 17 (who failed to respond).

Figure 1 presents response rate during test sessions as a function of training. The time from the beginning of the test until the first response was not included in deriving response rates. Figure 1 shows that keypecking increased with increased training under the VI schedule. The greatest increases occurred between 6 and 48 sessions. Only small differences in response rates were observed between 48 and 96 sessions and with extended training.
A main feature of the data was the variability in response rates observed among birds during testing sessions. Some pigeons (e.g., 23 and 27) showed high response rates in the presence of free food; others (e.g., 14 and 21) showed very low rates. Figure 1 also shows that there were no differences in response rates

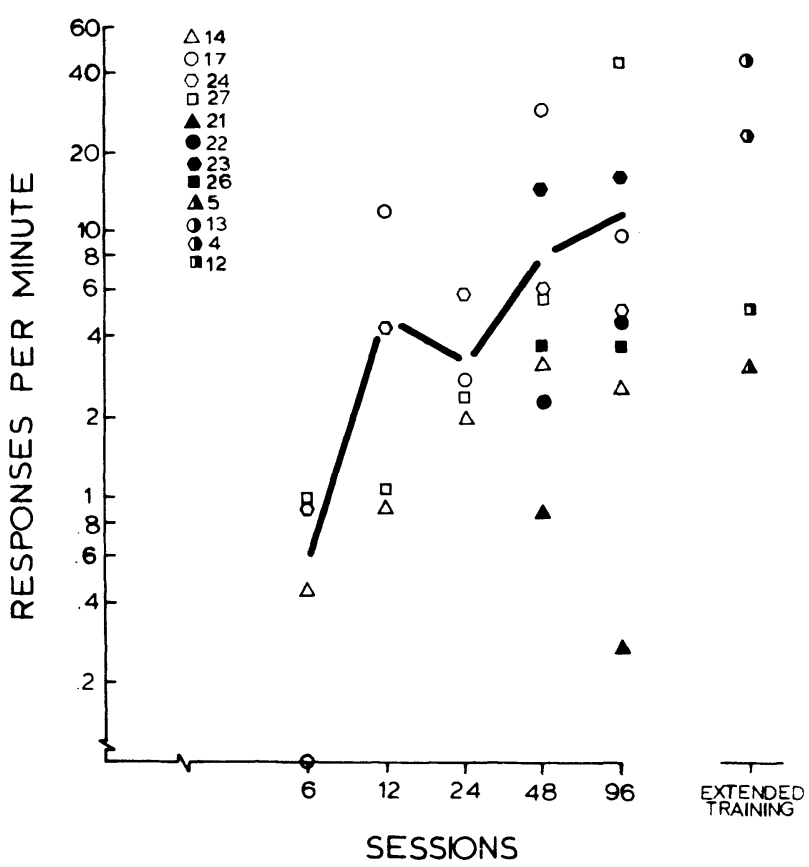

Figure 1. Response rate during the choice tests as a function of previous training sessions. The solid line joins the mean response rates for all birds tested after $6,12,24,48$, and 96 sessions under the VI schedule. "Extended training" represents pigeons with extensive experience under a fixed-interval schedule and 17 sessions under the VI schedule. Both axes are logarithmic.

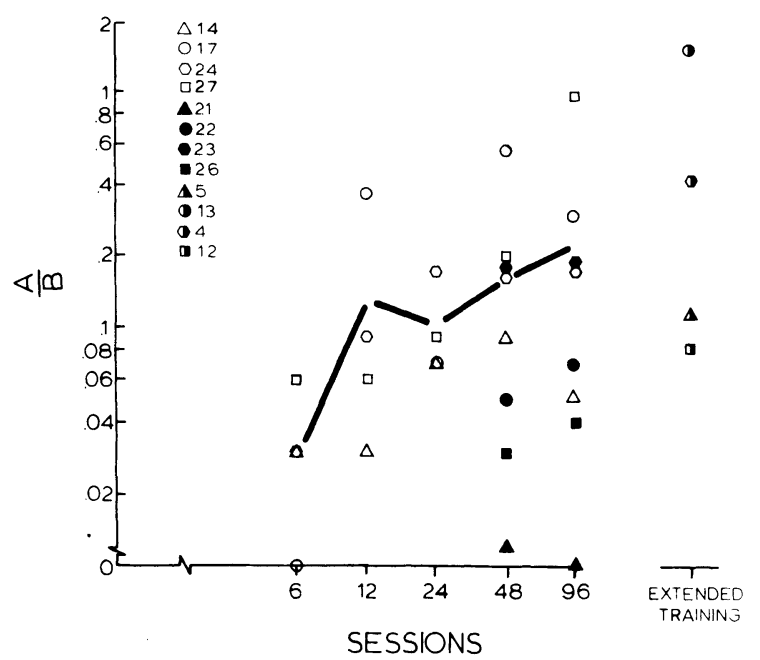

Figure 2. (A) The ratio of response rate during the choice test and (B) the mean response rate of the five sessions before the test, as a function of training sessions. The solid line joins the mean ratios for birds tested after $6,12,24,48$, and 96 sessions. Both axes are logarithmic. 
between pigeons tested only twice (Birds 21, 22, 23, and 26) and pigeons tested five times (Birds 14, 17, 24, and 27) during test after 48 and 96 training sessions.

Figure 2 shows the ratio of response rate during the test and the mean response rate for five sessions before the test as a function of training. This measure accounts for changes in response rates during the tests that might be attributed to systematic changes in response rates during training. A value of 1.0 indicates that responding during the test equaled response rates before free food was available, while a value of .5 indicates that response rates were half the value of prechoice rates. Figure 2 shows the same increasing trend and response variability observed in Figure 1.

\section{DISCUSSION}

The present data support studies showing that food will maintain responding in the presence of freely available food. The results further suggest that the effect is partially controlled by the amount of prior experience with response-dependent reinforcement, a variable previously suggested by Jensen (1963) and others (i.e., Jensen et al., 1970; Stolz \& Lott, 1964). The present data show that the largest increase in response rate in the presence of free food occurred between 6 and 48 sessions of VI training, and few differences were observed after 48 and 96 sessions and with extended training. Unlike other studies that used separate-groups designs, this study shows the acquisition of contrafreeloading within individual subjects.

These findings suggest that differences in the amount of prechoice training could account for some of the variability among studies. Studies reporting high response rates in the presence of free food sometimes used animals from previous experiments (e.g., Neuringer, 1970) or animals extensively trained for the choice test (Davidson, 1971), whereas studies reporting little responding used animals with limited experience (e.g., Koffer \& Coulson, 1971). For example, Davidson (1971) gave rats 56 sessions of training and observed high response rates in the presence of free food, whereas Koffer and Coulson (1971) gave four naive cats from 5 to 15 sessions of training and observed few responses with free food available. These studies differ in many respects, and it is impossible to attribute the different results solely to training difference.

While it is clear that prechoice training plays a role in contrafreeloading, it is difficult to determine how much of a role. Some studies have shown that animals with no experience can acquire a response (without shaping) in the presence of free food (Coburn \& Tarte, 1976; Neuringer, 1969). Thus, while prechoice training may contribute to the contrafreeloading phenomenon, it is not always necessary. It is likely that prechoice training interacts with other variables, such as sensory feedback that accompanies response-dependent food.

Some authors (e.g., Alferink et al., 1973; Osborne \& Shelby, 1975) have argued that the sensory feedback (e.g., the sound of a feeder mechanism) that accompanies food may acquire reinforcing properties and that conditioned reinforcement may help maintain responding in the presence of free food. The present data are consistent with this interpretation. Responding produced food accompanied by the offset of the houselight and keylight plus the operation of the food hopper and hopper light. Increases in responding may have resulted from an increase in the number of times the brief-stimulus complex was paired with food during training. The between-subjects response variability observed within contrafreeloading experiments is reminiscent of the variability seen in the conditioned reinforcement literature (e.g., Cohen \& Lentz, 1976).
Although response rates during tests increased with training, there was considerable response variability among pigeons within the present study. For some pigeons response rates continued to increase until high rates were generated after 96 sessions. However, other pigeons responded at very low rates even after 96 sessions and extended training. This variability is a common characteristic of contrafreeloading research (e.g., Duncan \& Hughes, 1972).

\section{REFERENCES}

Alferink, L. A., Crossman, E. K., \& Cheney, C. D. Control of responding by a conditioned reinforcer in the presence of free food. Animal Learning \& Behavior, 1973, 1, 38-40.

Bilbrey, J. L., Patterson, D. D., \& Winokur, S. Maintenance and autoshaping of keypecking in undeprived pigeons. Bulletin of the Psychonomic Society, 1973, 2, 394-396.

Carder, B., \& Berkowitz, K. Rats' preference for earned in comparison with free food. Science, 1970, 167, 1273-1274.

Catania, A. C., \& Reynolds, G. S. A quantitative analysis of the responding maintained by interval schedules of reinforcement. Journal of the Experimental Analysis of Behavior, 1968, $11,327-383$.

Coburn, J. F., \& Tarte, R. D. The effect of rearing environments on the contrafreeloading phenomenon in rats. Journal of the Experimental Analysis of Behavior, 1976, 26, 289-294.

Cohen, S. L., \& Lentz, B. E. Factors influencing responding under multiple schedules of conditioned and unconditioned reinforcement. Journal of the Experimental Analysis of Behavior, 1976, 26, 395-404.

Davidson, A. B. Factors affecting keypress responding by rats in the presence of free food. Psychonomic Science, 1971, 24, 135-137.

Duncan, I. J. H., \& Hughes, B. O. Free and operant feeding in domestic fowls. Animal Behaviour, 1972, 20, 775-777.

Hothersall, D., Huey, D., \& Thatcher, K. The preference of rats for free or response-produced food. Animal Learning \& Behavior, 1973, 1, 241-243.

Jensen, G. D. Preference for bar pressing over "freeloading" as a function of number of rewarded presses. Journal of Experimental Psychology, 1963, 65, 451-454.

Jensen, G. D., Leung, C. M., \& Hess, D. T. "Freeloading" in the Skinner box contrasted with freeloading in the runway. Psychological Reports, 1970, 27, 67-73.

Koffer, K., \& Coulson, G. Feline indolence: Cats prefer free to response-produced food. Psychonomic Science, 1971, 24, 41-42.

Leung, C. M., Jensen, G. D., \& TAPLey, R. P. "Freeloading" in a runway as a function of amount of training and type of reinforcement schedule. Psychological Reports, 1968, 22, 211214.

Neuringer, A. J. Animals respond for food in the presence of free food. Science, 1969, 166, 399-401.

Neuringer, A. J. Many responses per food reward with free food present. Science, 1970, 169, 503-504.

Osborne, S. R. The free food (contrafreeloading) phenomenon: A review and analysis. Animal Learning \& Behavior, 1977, 5, 221-235.

Osborne, S. R., \& Shelby, M. Stimulus change as a factor in response maintenance with free food available. Journal of the Experimental Analysis of Behavior, 1975, 24, 17-21.

Stolz, S. B., \& LoTT, D. F. Establishment in rats of a persistent response producing a net loss of reinforcement. Journal of Comparative and Physiological Psychology, 1964, 57, 147-149.

(Received for publication October 29, 1979.) 